\title{
Indústrias de defesa na França \\ e na Europa: emergência, mutação, perspectivas de evolução
}

\author{
Defense industries in France \\ and Europe: emergence, mutation, \\ evolution prospects
}

HÉLÈNE MASSON*

Tradução do original em francês de Lis Barreto

\section{A "BASE INDUSTRIAL DE DEFESA": DEFINIÇÕES}

Até o decênio de 2000, em meio à vasta literatura de economia de defesa, a questão da empresa de armamento é raramente abordada. Isto decorre da dificuldade de apreender os contornos das atividades industriais e tecnológicas de defesa (o perímetro desta base) e, portanto, de mensurar precisamente estas mesmas atividades.

A primeira definição de "base industrial de defesa" foi dada por John Dunne, professor da Universidade de Leeds no Reino Unido, ${ }^{2}$ em 1995. Nesta definição, são colocadas juntas empresas dependentes, em diferentes níveis, do orçamento de defesa, e cujo Estado é tributário com o intento de obter os equipamentos que lhe são necessários para atender sua função de Defesa nacional.

Dunne propôs, neste contexto, classificar os produtos da BID, levando em consideração a relação destes com a ação militar e a guerra. Ele os separa em três grupos:

1 - As unidades que contribuem para a produção de sistemas de armas e dos equipamentos letais (da P\&D até a manutenção);

2 - As unidades que fornecem produtos não letais, mas estratégicos

* Chefe de pesquisa na Fundação para estudos estratégicos (FRS ${ }^{1}$ ) e diretor do polo de Defesa e Indústrias. 
(combustíveis, veículos);

3 - As unidades que fornecem produtos correntemente utilizados pelas Forças (alimentos, vestimentas).

Na França, por exemplo, os estudos sobre a base industrial de defesa (ou sobre a base tecnológica e industrial da defesa) se interessam, em sua maioria, pelo primeiro grupo, e o fazem por várias razões:

- Ele inclui as unidades que permitem, através dos programas de armamento, a autonomia estratégica;

- Ele é diretamente afetado pelas escolhas dos equipamentos militares;

- Ele representa o coração das habilidades da indústria de defesa e da pesquisa e desenvolvimento.

Entretanto, o setor industrial de armamentos possui problemas de identificação e de delimitação em razão da dificuldade de determinar precisamente o caráter militar ou civil de certos materiais. É antes pela destinação dos produtos do que por suas naturezas intrínsecas, suas características, ou ainda pelas tecnologias que incorporam, que se permite classificá-los como “armamento". Se é claro que um míssil ou um submarino são armamento, a distinção é mais difícil para outros equipamentos, notadamente os da área eletrônica, como os sistemas de telecomunicação, radares, eletrônica incorporada, equipamentos aeronáuticos.

O setor industrial de armamentos possui problemas de identificação e delimitação também porque o pertencimento das empresas a este setor não exclui seu pertencimento simultâneo a um ou vários outros setores industriais. Às dificuldades sobre a definição dos materiais se soma ainda outra dificuldade, que resta no fato de que a maioria das empresas que projetam, fabricam e montam estes materiais possuem atividades diversificadas.

Logo, a dificuldade em definir a base industrial de defesa tem, como consequência direta, a dificuldade de mensurar o peso desta indústria, ou seja, constituir os agregados e indicadores estatísticos confiáveis e consolidados. Ajunta-se, igualmente, a dificuldade de acesso a informação em razão da sensibilidade do setor (caráter estratégico).

Entretanto, qualquer que seja a definição, certas características do mercado de defesa o diferenciam da maior parte dos outros mercados. Ele possui papel central no Estado.

\section{O PAPEL CENTRAL DO ESTADO}

A razão de ser do setor de defesa é produzir os meios da defesa, sen- 
do, então, uma ferramenta para a política de defesa. Pela expressão da demanda pública de armamento, por sua forma, seu conteúdo, seu volume, o Estado estabelece o nível de ambição para a defesa e o nível de autonomia desejada, ou seja, seu nível de independência.

Esta noção de autonomia envolve o controle nacional da capacidade de concepção, de produção e de suporte de equipamentos, produtos, componentes. Ele resulta das exigências particulares na área da segurança do aprovisionamento. A aquisição de equipamentos de defesa possui, de fato, uma dimensão política muito forte; dimensão também reforçada pelas exportações de armamentos (significação política e diplomática, papel do Estado na área do controle das exportações).

Atribui-se às empresas de defesa um valor econômico e um valor estratégico; valores de grande importância que esta indústria detém são ativos específicos, quer sejam os ativos produtivos físicos (equipamentos industriais caros), os ativos humanos (pessoal qualificado) e os ativos imateriais (know-how, experiência, patentes, etc).

Segundo Jean Paul Hebert, ${ }^{3}$ economista francês, historicamente o princípio de uma supervisão pública do setor de armamentos visava atender a quatro objetivos principais:

- Um objetivo político: Não depender jamais de uma decisão estrangeira na área de equipamento militar.

- Um objetivo tecnológico: A conservação de uma vantagem na área das tecnologias militares, assegurando um máximo de confidencialidade a estas técnicas.

- Um objetivo militar: O Estado deve a todo instante conservar a capacidade de construir uma força de reação eficaz em resposta a toda ameaça súbita.

- Um objetivo econômico e industrial: a evolução do setor industrial tem consequências sobre o emprego ou o desenvolvimento regional.

O Estado representa um cliente único dos bens e serviços produzidos pelas empresas de defesa. Sua ação é, então, determinante para a emergência, o desenvolvimento e a perenidade das atividades industriais e tecnológicas de defesa. Esta intervenção pública é nítida hoje em dia entre os Estados produtores de armamento e entre os países que procuram possuí-los. Paul Dunne estipula, dentro desta expectativa que:

O Estado pode influenciar o tamanho da indústria, da sua estrutura, as entradas e as saídas, os preços e os lucros, a eficácia, 
a propriedade e o nível técnico, através de sua decisão de aquisição (o que, a quem, a que preço) e outras políticas mais globais.

O Estado desenrola, assim, um papel determinante no desenvolvimento e na atividade do setor industrial, através de sua política de sustentação da pesquisa, do desenvolvimento e da inovação, como também de sua política de aquisição - dois pilares da política industrial.

\section{FRANÇA: EMERGÊNCIA E MUTAÇÃO DA INDÚSTRIA DE DEFESA}

Historicamente, a indústria francesa de defesa é marcada pela importância do papel do Estado na sua constituição e no seu funcionamento, tanto pelo volume de crédito quanto pela produção que depende do Estado dentro dos arsenais e das empresas nacionalizadas.

\subsection{Fatores de emergência}

Recordamos que a indústria de armamentos foi reinventada sob novas bases após a Segunda Guerra Mundial. A ambição tecnológica é muito forte. Empresas como a construtora de motores Snecma foram nacionalizadas. As empresas nacionalizadas em 1936 foram reinventadas por seus próprios proprietários, como os aviões Marcel Dassault. Organismos públicos de pesquisa surgem em 1945: a Comissão de Energia Atômica (CEA), cuja uma das principais missões era dotar a França de arma nuclear, e o Escritório Nacional de Estudos e Pesquisas na área Aeronáutica (ONERA ${ }^{4}$ ).

Além disso, o que permitiu o desenvolvimento rápido da pesquisa militar foi a centralização, a um nível elevado, das decisões relativas ao programa de armamentos, com a criação, em 1961, da Delegação Ministerial de Armamentos (DMA), dirigida por um engenheiro de posição igual à de Chefe do Estado Maior das Armas, e com a criação da Direção de pesquisa e meios de testes $\left(\mathrm{DRME}^{5}\right)$, encarregada da coordenação de todas as atividades de $\mathrm{P} \& \mathrm{D}$ e da inovação militar. Neste contexto, grandes programas foram iniciados na área nuclear, militar clássica e espacial (absorvendo até $80 \%$ do orçamento da pesquisa francesa até os anos 1980). Grandes programas (de duração superior a 20 anos), procedimentos e mecanismos específicos, dirigidos pela DMA/DRME (fundidas em 1977 para formar a Delegação Geral para o Armamento, DGA), permitiram, desta forma, 
organizar a produção de armamentos e manter longe dos constrangimentos econômicos as indústrias da área. Este processo foi acompanhado por uma reestruturação profunda da base industrial e dos investimentos no setor público e público-privado. O sistema se caracterizou, então, por uma concentração da autoridade e dos meios, em especial ao seio da DGA, considerado como a interface entre as Forças Armadas, a indústria e os laboratórios de pesquisa. O objetivo era favorecer o melhor emprego dos homens, um rendimento mais elevado das infraestruturas industriais e uma utilização racional dos créditos.

Além do mais, nos anos de 1960, o ministério da Defesa foi dotado de duas ferramentas de planificação: uma planificação de longo prazo, em um horizonte de 15-20 anos, e a lei de programação militar, em um prazo de 5 anos. Estas ferramentas oferecem uma maior visibilidade aos atores do setor.

\subsection{Anos 1950 - 1980: grandes programas, indústrias de defesa e independência nacional}

A indústria de armamentos sofreu uma forte expansão nos anos de 1950 e ao longo dos anos 1960, ligada ao lançamento de grandes programas marcados pela vontade de independência nacional do período de Charles de Gaulle. O sistema encontrou seu equilíbrio em um "modo de regulação administrada” (anos 1950 - anos 1980), segundo Jean Paul Hébert. Eram os imperativos de performances técnicas, especificações operacionais e autonomia das condições de produção que prevaleciam sobre outras considerações (normalmente a concorrência e o mecanismo de preços). Quais são suas principais características?

- Depois dos anos 1960, um movimento de concentração industrial vê a constituição de um produtor principal para cada tipo de produção, líder em seu setor: Thomson (eletrônica), DCN (naval), Aerospatiale (aeronáutico), Dassault aviation (aviação de combate), GIAT Industries (terrestre). Estes cinco grupos realizaram, sozinhos, cerca de dois terços da produção total de armamentos da França durante este período.

- Se as atividades industriais de armamentos na França são asseguradas pelas instituições do setor público e pelas empresas industriais privadas, nós constatamos a persistência de um setor público dominante. Este último compreende as instituições do Estado ou arsenais (regras de direito público, parte integrante do Estado, geradas diretamente pela DGA), das 
instituições públicas (empresas de propriedade do Estado, dotadas de personalidade jurídica, sujeitas às regras do direito privado) e das empresas nacionais (detenção pelo Estado, de maneira direta ou indireta, da maioria das ações, regidas pelo direito privado; status de sociedade anônima).

- Os mercados públicos são os mais comumente notificados, segundo um processo de não concorrência.

\subsection{Fim dos anos 1980 - Decênio 1990: Um setor em plena mutação}

Ao fim dos anos 1980 e ao meio dos anos 1990, este modo de regulação é questionado. Quais são as principais causa?

- Contexto de ajuste e da contração das despesas militares, aumento dos custos de $\mathrm{P} \& \mathrm{D}$.

- Pressão europeia ligada à criação, entre 1987 e 1993, de megagrupos no Reino Unido (British Aerospace e GEC) e na Alemanha (DASA), notadamente. Os industriais franceses colocam em curso uma estratégia de alianças ao nível europeu, estratégia que foi facilitada pelo lançamento de programas em cooperação. Ao longo dos anos 1980, alguns programas multilaterais deram lugar à criação de filiais comuns $\left(\mathrm{GIE}^{6}\right)$. Um passo importante foi dado com a criação de joint ventures e das sociedades comuns baseadas no mesmo tipo de negócio, ${ }^{7}$ resultado da fusão de divisões ou filiais dos "campeões nacionais".

- Contestação do papel econômico do Estado e deslegitimação do setor público, tendo por consequência um desengajamento estatal no setor industrial (transformação das instituições industriais em sociedades anônimas, como as indústrias GIAT, e abertura do capital de certas empresas como a Aerospatiale, Snecma e Thomson).

\subsection{A virada dos anos 1998-2000: do nacional ao europeu}

Os anos 1998-2000 representam uma verdadeira virada. Os Estados europeus produtores de armamentos, como a França, constataram neste período uma forte dispersão do setor. Frente aos seus concorrentes americanos, as empresas europeias não dispunham nem de tamanho suficiente, nem de uma gama de produtos suficientemente larga que lhes permitisse serem competitivos em um número importante de segmentos do mercado. De fato, do outro lado do Atlântico, um movimento de reestruturação im- 
portante, lançado em 1991, deu luz a quatro grandes players industriais: Boeing, Lockheed Martin, Northrop Grumman, Raytheon.

$\mathrm{O}$ setor industrial europeu de defesa se engajou, na virada dos anos 2000, em um movimento de concentração, inicialmente desejado e impulsionado pelos Estados. Estas operações de aproximação concerniam, sobretudo, aos setores eletrônicos e aeronáuticos, caracterizados pela importância e pelos custos de P\&D. Três grandes grupos europeus de dimensão mundial emergiam: BAE Systems, Thales e EADS.

- Privilegiando uma estratégia de concentração vertical e de centralização dos segmentos de atividades de defesa, a BAE absorve, em 1999, os ativos eletrônicos de defesa da General Electric Company (GEC)-Marconi, tornando-se a BAE Systems.

- Este novo ambiente concorrencial impôs à francesa Thompson-CSF a adaptação a uma estratégia dita "multidoméstica”. Esta estratégia se traduz por uma importante política de compras, aquisições e de participação em empresas estrangeiras (Reino Unido, Coreia do Sul, Singapura, África do Sul). A aquisição por $\mathrm{OPA}^{8}$ da empresa britânica Racal Electronics deu à empresa Thomson-CSF, rebatizada de Thales $^{9}$, a dimensão internacional tão almejada.

- A European Aeronautic Defence and Space Company (EADS) resulta da fusão da alemã DASA, da francesa Aérospatiale Malta e da espanhola CASA. A existência, durante de vários anos, de uma colaboração entre a Aérospatiale, CASA e DASA, criou um ambiente favorável. Em 1998, estes três grupos significaram mais de dois terços de suas atividades em comum, através de acordos comerciais, de joint ventures (JV) ad hoc, ou de alianças por tipo de negócio. Em 8 de julho de 2000, a fusão da Aérospatiale Matra, da alemã DASA e dos ativos aeronáuticos do holding público espanhol SEPI (CASA) é definitivamente selada e dá vida à EADS, a número dois no mundo e primeira empresa europeia na área da aeronáutica, da defesa e no campo espacial. A estratégia de consolidação da EADS deu luz a dois líderes europeus, sendo um na construção de satélites, ASTRIUM, e outro na área de mísseis e sistemas missilísticos, MBDA.

Além disso, na Itália e na Suécia, uma concentração das atividades industriais e tecnológicas ao nível nacional resultou na criação dos conglomerados Finmeccanica e SAAB AB. Cada um destes concentra mais de $80 \%$ das capacidades industriais nacionais.

Passamos, então, neste período, de uma regulação administrada a uma regulação concorrencial, uma mutação que se acelera ainda mais ao longo 
dos anos 2000. O setor se caracteriza como:

- Preeminência da lógica financeira e da economia de mercado;

- Abertura de capital e recomposição acionária das empresas no contexto de um desengajamento progressivo do Estado (mas o Estado Francês manteve-se presente no capital das empresas mais estratégicas: Nexter, DCNS, Thales, EADS, Safran, SNPE).

- Busca pelo tamanho crítico das empresas e por melhores sinergias internas;

- Vendas de ativos não rentáveis e/ou muito distantes do coração do negócio;

- Operações externas para a aquisição de títulos de seguimentos em crescimento;

- Importância das vendas para a exportação.
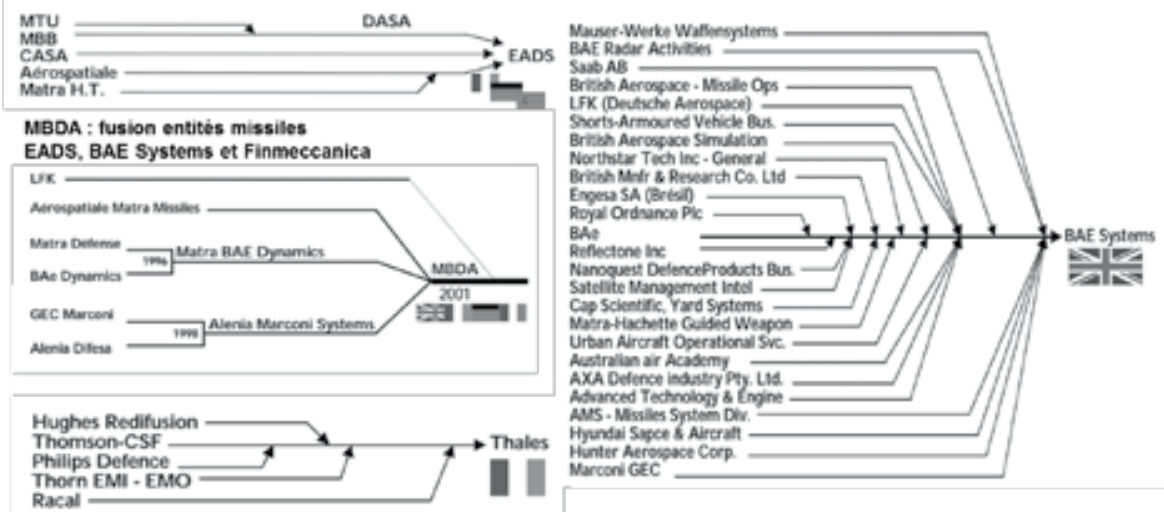

\section{ESTRUTURA DE OFERTAS E AS RELAÇÕES ESTADO/INDÚSTRIAS}

Este movimento de concentração industrial ao nível europeu que engajou a virada dos anos 2000 sob o impulso dos Estados é traduzido, logicamente, por uma concentração de vários fornecedores da Europa, apesar da existência de um único fornecedor em cada nacionalidade. Uma vez que não há novas fusões entre as principais empresas e montadoras de classificação 1 nos setores de aeronáutica e eletrônica (exceto a criação do grupo Safra em 2000), a maioria da operações ocorre no seio da cadeia de 


\begin{tabular}{|c|c|c|c|c|c|c|}
\hline AEROSPATLAL & $\mathbf{F R}$ & Esp & $\mathrm{AL}$ & UK & IT & SU \\
\hline Aviões de Conbqte & $\begin{array}{l}\text { Dassault } \\
\text { Aviation }\end{array}$ & \multicolumn{4}{|c|}{$\begin{array}{l}\text { BAE Systems + Finmeccanica/Alenia Aeronautica + } \\
\text { EADS/Cassidian (Eurofighter GmbH) }\end{array}$} & SAAB AB \\
\hline Aviões de treinamento & & & & BAES & Finm. /Alenis & \\
\hline $\begin{array}{l}\text { Aviס̃es de transporte } \\
\text { pesados }\end{array}$ & \multicolumn{4}{|c|}{ EADS/Airbus Military } & & \\
\hline Helicopteros & \multicolumn{3}{|c|}{ EADS/Eurocopter } & \multicolumn{2}{|c|}{ Finm./Agusta Westland } & \\
\hline Misseis & $\begin{array}{l}\text { MBDA } \\
\text { Safran }\end{array}$ & & $\begin{array}{l}\text { MBDA } \\
\text { aieht BOT }\end{array}$ & $\begin{array}{l}\text { MBDA } \\
\text { Thales UK/ } \\
\text { Roytheon }\end{array}$ & MBDA & $S a c b B D$ \\
\hline Drones (MTOW < 2T) & \multicolumn{6}{|c|}{ Fournisseurs multiples } \\
\hline Drones (MTOW >2T) & $\begin{array}{l}\text { Dassault } \\
\text { Aviation }\end{array}$ & & EADS & BAE Systems & Finm. /Alenia & \\
\hline Espacial & $\begin{array}{c}\text { EADS Astrium } \\
\text { Thales Alenia } \\
\text { Space }\end{array}$ & $\begin{array}{l}\text { EADS } \\
\text { Astrium }\end{array}$ & $\begin{array}{l}\text { EADS } \\
\text { Astrium } \\
\text { OHB }\end{array}$ & $\begin{array}{l}\text { EADS } \\
\text { Astrium }\end{array}$ & $\begin{array}{l}\text { Thales Alenia } \\
\text { Space }\end{array}$ & \\
\hline \multirow[t]{2}{*}{ motores } & $\begin{array}{l}\text { SAFRAN/ } \\
\text { Snecma }\end{array}$ & & & $\begin{array}{l}\text { Rolls Royce } \\
\text { (ochat MTU) }\end{array}$ & $\begin{array}{c}\text { Avio } \\
\text { (rocheté por GE) }\end{array}$ & \\
\hline & \multicolumn{6}{|c|}{ + Bases équipementières (sous-traitants) } \\
\hline
\end{tabular}

\begin{tabular}{|c|c|c|c|c|c|c|}
\hline TERRESTRE & $\mathbf{F R}$ & Esp & $\mathbf{A L}$ & UK & IT & SU \\
\hline Char de combat principal & Nexter & GDELS & KMW & $\begin{array}{l}\text { BAES } \\
\text { GDELS }\end{array}$ & & \\
\hline $\begin{array}{l}\text { Véhicules de combat } \\
\text { d'infanterie chenillés }\end{array}$ & & GDELS & KMW & GDELS & $\begin{array}{c}\text { Oto } \\
\text { Melara/liveco }\end{array}$ & $\begin{array}{c}\text { BAES } \\
\text { Hăgglunds }\end{array}$ \\
\hline $\begin{array}{l}\text { Véhicules à roues (Vegerh, } \\
\text { mevent bindes, tranaport blinsie) }\end{array}$ & $\begin{array}{l}\text { Nexter } \\
\text { RTD/Panhard }\end{array}$ & GDELS & $\begin{array}{c}\text { KMW } \\
\text { Rheinmetall }\end{array}$ & GDELS & $\begin{array}{c}\text { Oto } \\
\text { Melara/lueco }\end{array}$ & \\
\hline $\begin{array}{l}\text { Système d'artillerie/canon } \\
\text { automoteur }\end{array}$ & Nexter & GDELS & $\begin{array}{c}\text { KMW } \\
\text { Rheinmetall }\end{array}$ & GDELS & Oto Melera & BAES Bofors \\
\hline
\end{tabular}

\begin{tabular}{|c|c|c|c|c|c|}
\hline NAVAL & $\mathbf{F R}$ & Esp & AL & UK & IT \\
\hline $\begin{array}{l}\text { Submarino nuclear } \\
\text { estrategico }\end{array}$ & DCNS & & & $\begin{array}{l}\text { BAE Systems } \\
\text { Babookk [MCO) }\end{array}$ & \\
\hline $\begin{array}{l}\text { Submarino Nuclear de } \\
\text { Ataque }\end{array}$ & DCNS & & & $\begin{array}{l}\text { BAE Systems } \\
\text { Bobcock (Mco) }\end{array}$ & \\
\hline $\begin{array}{l}\text { Submarinos com propulsð̊o } \\
\text { diesel-electrico }\end{array}$ & DCNS & $\begin{array}{l}\text { Navantia } \\
\text { [ttockliced] }\end{array}$ & TKMS & $\begin{array}{l}\text { Fincantieri } \\
\text { (coop. It/ail }]\end{array}$ & \\
\hline Navios Aérodromos & DCNS & Navantia & TKMS & $\begin{array}{l}\text { BAE Systems } \\
\text { Babcock }\end{array}$ & Fincantieri \\
\hline Navires desuperficie & $\begin{array}{c}\text { DCNS } \\
\text { STX Europe }\end{array}$ & Navantia & $\begin{array}{l}\text { TKMS } \\
\text { türssen }\end{array}$ & BAE Systems & Fincantieri \\
\hline
\end{tabular}

\section{+ base de equipqmentos (subcontratados) organisados sob uma base nacional}

subcontratados do nível 2 e 3 , e dentro perspectiva futura de consolidação dos setores naval e de armamentos terrestres.

Nos setores de aeronáutica e defesa, seis grandes grupos industriais geraram 120 bilhões de euros de vendas na Europa, sendo 3/4 do volume de 
negócios do setor em 2010: EADS, BAE Systems, Finmeccanica, Thales, e montadoras de motores Rolls Royce e Safran.

Neste contexto, as relações Estado/Indústrias evoluem. As empresas foram privatizadas em sua maioria. Os principais grupos são de capitais abertos. Seus clientes e suas atividades se diversificaram. Em resumo, o nível de dependência vis-à-vis do cliente doméstico diminuiu. As empresas de defesa são mais autônomas em seu funcionamento e em suas orientações estratégicas. Frente às empresas menos dependentes, o Estado passou de uma estratégia de intervenção direta e explícita (anos 1950-1990) a uma estratégia de influencia sobre o funcionamento das empresas, mais indireta e mais implícita. Ele se ocupa de uma política industrial de acompanhamento.

Contudo, estas mutações não se traduzem em uma ruptura da relação privilegiada entre o Estado e os principais fornecedores das Forças Armadas. É tanto que, na França, os 10 principais fornecedores das Forças Armadas (ar, terra e mar) representam, sozinhos, $80 \%$ da demanda pública francesa por armamentos (Dassault Aviation, EADS, Thales, Safran, Nexter, DCNS, RTD/Panhard, Areva TA, e SNPE). Esta situação é equivalente no Reino Unido, na Alemanha e ainda na Itália.

Entretanto, se a base tecnológica e industrial é importante na Europa, as ambições dos Estados produtores de armamento são divergentes. As despesas de P\&T representam a melhor ilustração, com uma predominância de dois Estados, França e Reino Unido. Lembrando que a França e o Reino Unido representam a metade dos gastos de defesa na Europa, 80\% das despesas de P\&D, 90\% da capacidade de projeção militar e os contribuintes mais ativos das operações no Afeganistão, na Líbia e em outros cenários em crise. Esta posição da França e do Reino Unido são igualmente encontradas nas áreas de investimento público em P\&T Defesa, totalizando $70 \%$ das despesas dos Estados. A Alemanha aparece em terceiro lugar. Por seu lado, a Suécia privilegia uma política de nichos.

Em períodos de contrações orçamentárias, estes Estados procuram otimizar recursos, concentrando os financiamentos nas tecnologias mais discriminantes e críticas. A ideia aqui é, para os Estados mais ambiciosos, de conservar uma vantagem tecnológica. Além desta concentração de financiamentos, os poderes públicos incentivam a promoção de parcerias empresas/universidades/laboratórios para a pesquisa, em uma lógica geográfica e de sinergias locais (polos de competitividade, aglomerados, distritos tecnológicos, parques científicos, etc.) que desenvolva sinergias com a pesquisa civil. No mais, o objetivo é privilegiar a cooperação internacional para as futuras gerações de equipamentos. 


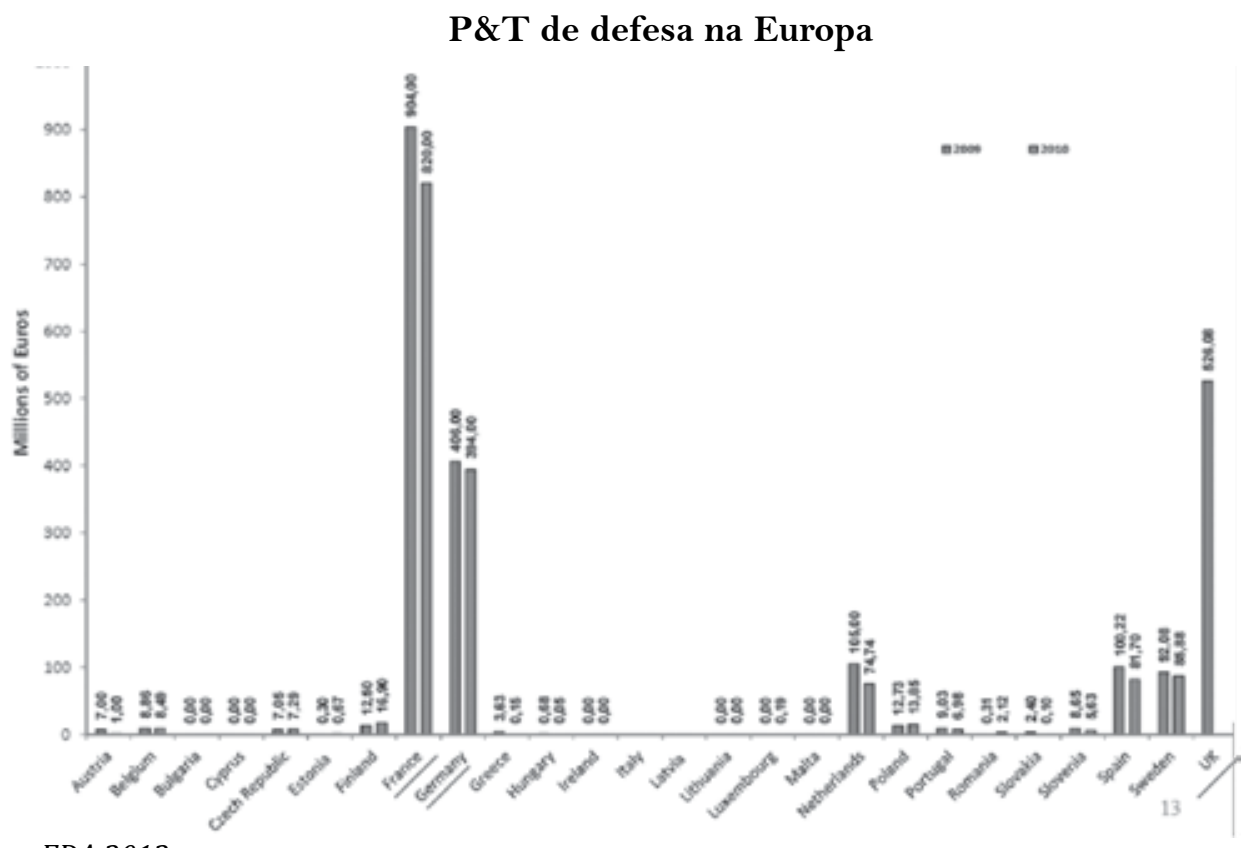

EDA 2012

Conclui-se que o setor industrial de defesa na Europa é confrontado com numerosos desafios:

- Atravessar uma nova etapa na consolidação do setor: racionalização e internacionalização da cadeia de subempreiteiros, operações de concentração no setor naval e de armamento terrestre;

- Encontrar a medida ideal entre uma política industrial de acompanhamento e a abertura dos mercados públicos de defesa à concorrência;

- Repensar as formas de aquisição para a nova geração de equipamentos (futuros programados), privilegiando a exportabilidade e a cooperação. De fato, a exportabilidade do equipamento parece surgir agora como o foco dos principais critérios para o lançamento de um programa. Além disso, é necessário considerar novos modos de cooperação e parceria com os Estados europeus, mas também com Estados de terceiro mundo como o Brasil. O Objetivo é tentar superar a simples lógica ligada à exportação de produtos (offsets, transferências de tecnologias), para privilegiar o lançamento de programas comuns de equipamentos com parceiros (financiamento, desenvolvimento e produção conjunta, conquista de terceiros mercados), a criação de firmas transnacionais, ou, ainda, o estabelecimento se parcerias/ consultorias específicas sobre os programas da nova geração. 


\section{NOTAS}

1. Fondation pour la recherche stratégique.

2. Paul Dunne, "The defense industrial base", Chapter 14 in Handbook of Defense Economics, Elsevier 1995, vol. 1, 399-430.

3. Hébert J.-P., "Etats et firmes d'armement en Europe". Cahier d'Etudes

Stratégiques, 22, Groupe de sociologie de la Défense de l'EHESS, CIRPES, 1998.

4. l'Office national d'études et de recherches dans le domaine aéronautique.

5. Direction des recherche et des moyens d'essais.

6. Airbus Industrie GIE (1970); Euromissile GIE (1980); Eurofighter Jagdflugzeug GmbH (1986); Eurosam GIE (1989).

7. Em 1990, Matra Marconi Space (Matra, GEC-Marconi); em 1991, Eurocopter ( DASA, Aerosptiale); em 1994, Thomson Dasa Armement (Thomson-Brandt Armement, Wirksystem); em 1996, Thomson Marconi Sonar (Thomson-Csf, GEC-Marconi); em 1996, Matra BAe Dynamics (Matra, BAe); em 1998, Alenia Marconi Systems (Finmeccanica, GEC-Marconi).

8. Aquisição por Oferta Pública.

9. Ver anexos, Folha Thales. 


\section{ANEXOS}

Empregos nos setores aeronáuticos (incluso civil) e defesa 2010

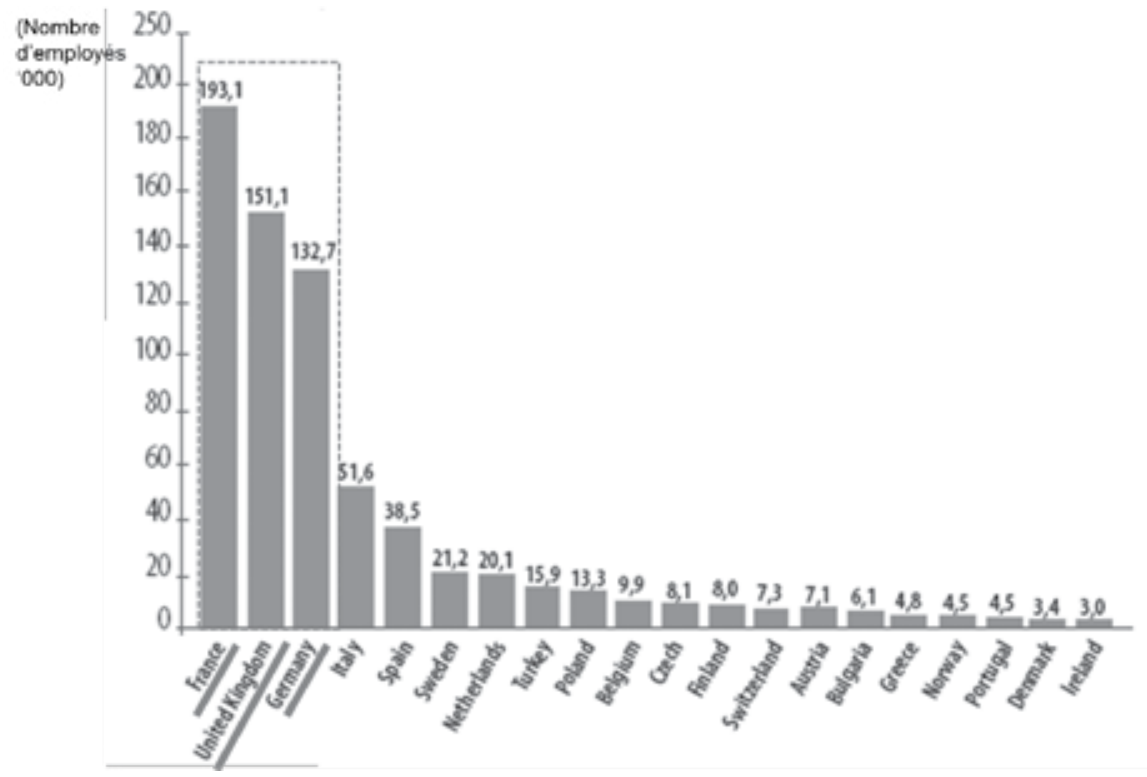

Source ASD 2011

Despesas de equipamento (2011) e base industrial

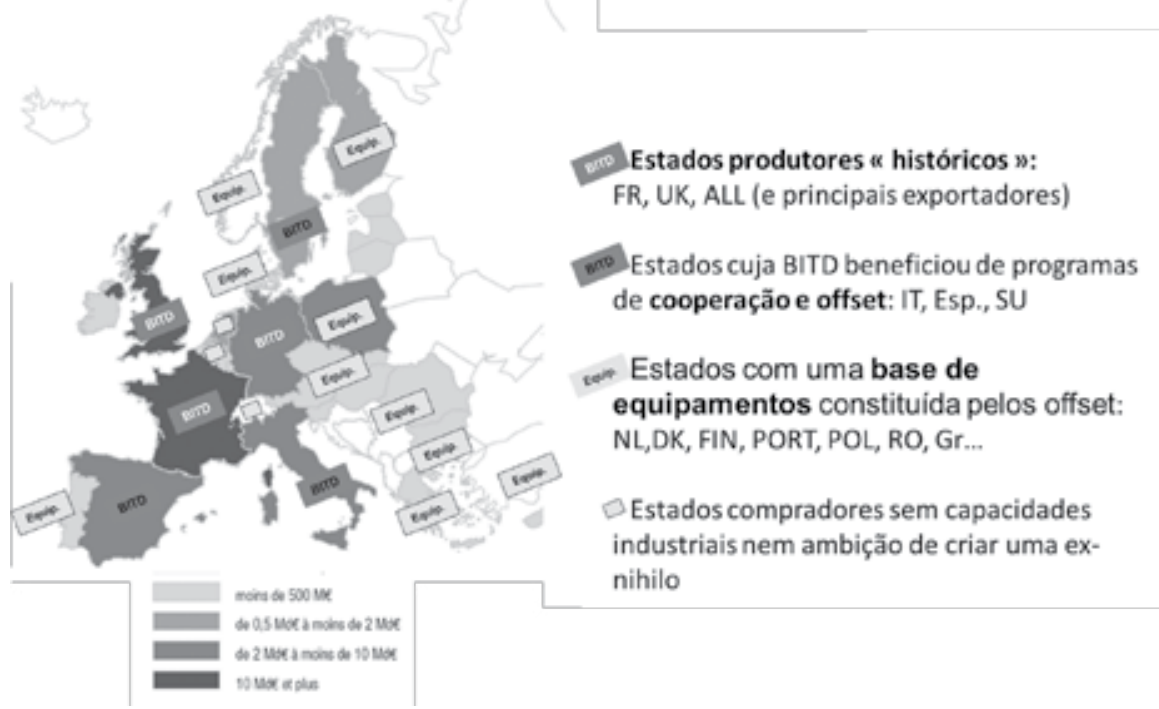


Emprego industrial e dinâmicas regionais

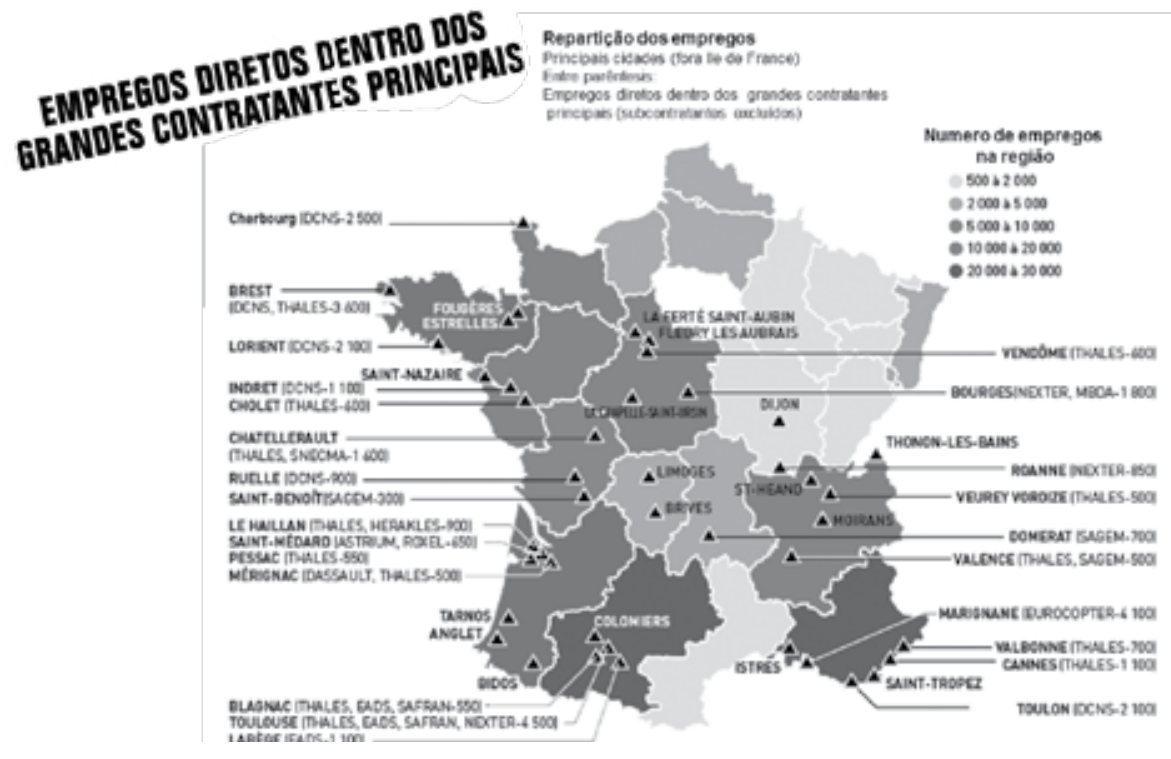

Fonte LPM 2014-2019 - Ministerio da Defesa francês

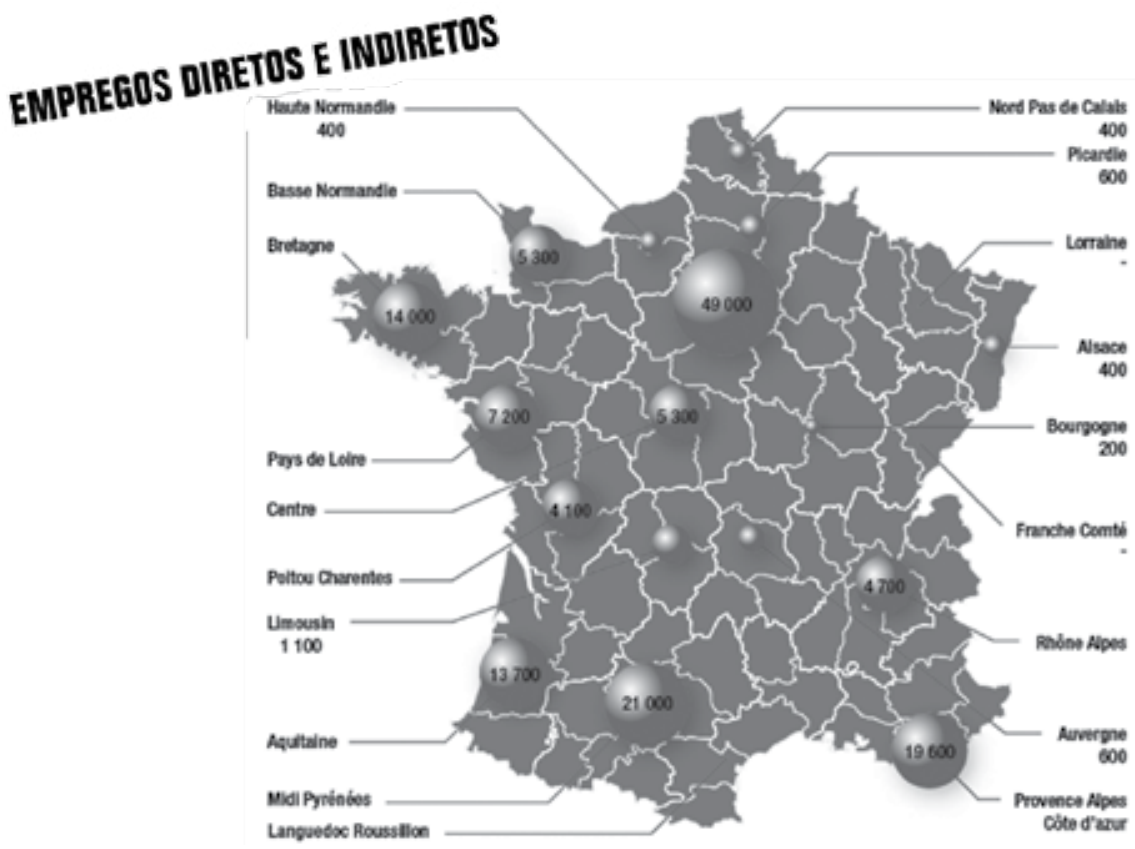

Fonte LPM 2014-2019 - Ministerio da Defesa francês 


\section{INDÚSTRIAS DE DEFESA NA FRANÇA E NA EUROPA: EMERGÊNCIA, MUTAÇÃO, PERSPECTIVAS DE EVOLUÇÃO}

\section{RESUMO}

Atualmente, os Estados europeus repensam suas políticas de defesa, as missões das Forças Armadas, os meios e as capacidades militares. Neste contexto, as autoridades governamentais se interrogam sobre o futuro da base industrial de defesa, notadamente sobre a melhor maneira de otimizar os recursos financeiros para sustentar as áreas industriais e tecnológicas de excelência. $\mathrm{O}$ artigo aborda as evoluções em curso na Europa a partir de quatro enfoques. Primeiramente, abordaremos o problema de definição do conceito de "base industrial de defesa". Em outra parte, tentaremos apreender o papel central dos Estados e das políticas públicas no setor de armamentos. A terceira seção incidirá mais especificamente sobre fatores da emergência da indústria da defesa na França. Enfim, a quarta seção irá tratar da estrutura de oferta na Europa e das relações Estado/Indústrias.

Palavras-chave: Políticas de Defesa. Forças Armadas. Indústria de Defesa. Base Industrial de Defesa.

\section{ABSTRACT}

Currently, European states rethink their defense policies, the missions of the armed forces, means and military capabilities. In this context, government authorities are questioning the future of the defense industrial base, especially on the best way to optimize financial resources to sustain the industrial and technological areas of excellence. The article discusses the current developments in Europe from four approaches. First, we discuss the problem of defining the concept of "defense industrial base". Elsewhere, try to grasp the central role of states and public policies in the armaments industry. The third section will focus more specifically on factors in the emergence of the defense industry in France. Finally, the fourth section will discuss the structure of supply in Europe and between the state/Industries.

Keywords: Defense Policy. Military. Defense Industry. Defense Industrial Base. 